\title{
Linking parasitism to network centrality and the impact of sampling
}

\section{bias in its interpretation}

Zhihong $\mathrm{Xu}^{1 *}$, Andrew J. J. MacIntosh ${ }^{1}$, Alba Castellano-Navarro², Emilio Macanás-Martínez ${ }^{2}$,

Takafumi Suzumura ${ }^{3}$, Julie Duboscq ${ }^{4,5}$

${ }^{1}$ Kyoto University Primate Research Institute, Inuyama, Japan.

${ }^{2}$ Ethology and Animal Welfare Section, Universidad Cardenal Herrera-CEU, CEU Universities, Valencia, Spain

${ }^{3}$ Kyoto University Wildlife Research Center, Kyoto, Japan.

${ }^{4}$ CNRS-MNHN-Université de Paris, UMR7206 Eco-anthropologie, Paris, France.

${ }^{5}$ Dept. Behavioral Ecology, Johann-Friedrich-Blumenbach Institute for Zoology and Anthropology, University of Göttingen, Göttingen, Germany

* corresponding author: Zhihong Xu, Kyoto University Primate Research Institute, Inuyama, Japan, zhihong.xu.36r@st.kyoto-u.ac.jp 


\begin{abstract}
Group living is beneficial for individuals, but also comes with costs. One such cost is the increased possibility of pathogen transmission, because increased numbers or frequencies of social contacts is often associated with increased parasite abundance or diversity. The social structure of a group or population has been shown to be paramount to patterns of infection and transmission. Yet, for various reasons, studies investigating the social transmission of parasites in animals, and especially in primates, have only taken into account parts of the group (e.g., only adults or even only adult females), which is likely to impact the interpretation of any results linking sociality and parasitism. Here, we investigated the relationship between social network centrality and an estimate of gastrointestinal helminth infection intensity in a complete group of Japanese macaques (Macaca fuscata). We then tested the impact of missing parts of the group on this relationship. We aimed to test: (1) whether social network centrality - the number of partners (degree), frequency of interactions (strength) and level of social integration (eigenvector) - was linked to parasite infection intensity; and, (2) to what extent excluding all or portions of individuals within the group from the analyses might influence the observed relationship. We conducted social network analysis on data collected from one complete group of Japanese macaques over two months on Koshima Island, Japan, to relate metrics of network centrality to an index of parasite infection intensity (eggs per gram of feces: EPG). We then ran a series of knock-out simulations to test the effect(s) of accounting only for certain age-sex classes on the observed relationship. General linear mixed models showed that, in the complete network, centrality was positively associated with infection by the examined geohelminths (Oesophagostomum aculeatum, Trichuris trichiura and Strongyloides fuelleborni), but in partial networks with only adult females, only juveniles, or random subsets of the group, the strength of this relationship - albeit still positive - lost statistical significance. Our study indicates that sampling bias can impact the relationship that is observed between social interaction and parasitism. In addition to supporting earlier results linking geohelminths to Japanese macaque social networks, this work introduces important methodological considerations for research into the dynamics of social transmission, with applications to infectious disease epidemiology, population management, and health interventions.
\end{abstract}

Key words: sociality, social network, geohelminth, Knock-out simulation, sampling bias 


\section{Introduction}

Living in groups provides many benefits to individuals, but it can also come with costs (Loehle, 1995). One such cost is increased exposure to parasites and a higher probability of parasite transmission from one individual to another (Altizer et al., 2003; Arneberg et al., 1998; Freeland, 1976; Loehle, 1995) This pattern may arise from higher contact rates between individuals and generally higher local densities of hosts, from increased numbers of social partners and relevant social interactions, or even from the perspective of vectors of parasites, from increased attractiveness of an aggregation of hosts (Altizer et al., 2003; Arneberg, 2002). Even for parasites that are not transmitted through direct contact between hosts, sharing of resources and space, such as sleeping sites or home ranges, increases the likelihood of encountering infectious stages of parasites in the environment, which increases the probability of transmission between hosts (Altizer et al., 2003; Müller Klein et al., 2019; Nunn et al., 2015).

Within a group, individuals exhibit different rates of interacting, leading to differences between potential contacts and actual contacts. Because of which, the positive relationship that is expected to occur between increased group size and increased parasitism is not always observed (Moller et al., 1993). Social interactions tend to be structured according to kinship ties, dominance hierarchies, or age-, sizeand sex-biased assortativity. The resulting social structure not only influences each individual's exposure to parasites, but also its probability of becoming infected once exposed, i.e., its susceptibility to infection. Accounting for social structure and the role and position of individuals within it therefore helps making sense of how parasites are transmitted within animal groups. This can also provide more information about the impact of social behaviour on the spread of parasites and, conversely, the role of parasites in the evolution of animal behaviour. 
In this endeavour, Social Network Analysis (SNA) is an efficient statistical tool that can analyse groups of individuals as a whole and help make predictions about the spread of infectious diseases (Borgatti, 2005). Social networks reflect the patterns of interactions, associations, or spatial proximity between social individuals. SNA can provide information about the whole structure of the network, but also analyse the structural importance of certain nodes (e.g. individuals) and their ties (e.g. interactions) to identify influential individuals within a network (Borgatti et al., 2009). So-called central individuals have qualitatively or quantitatively greater direct or indirect connections than less central or peripheral individuals. An individual's direct connections can vary in both degree, i.e., the cumulative number of unique interaction partners, and strength, i.e., the frequency with which the individual interacts with its partners. An individual's indirect connections further consider the relative degrees and strengths of those individuals to which it is connected. Central individuals are thus expected to be at once key dispersers of parasites but also at the greatest risk of acquiring parasites from others (Romano et al., 2016). For example, gidgee skinks (Egernia stokesii) with high refuge-sharing rates are more likely to be infected by ticks and host a more diverse blood parasite community than less-connected skinks in the same refuge-sharing network (Godfrey et al., 2009). Similarly, female Japanese macaques (Macaca fuscata yakui) that are better connected in their grooming networks exhibit more diverse intestinal helminth communities and greater intensity of infection with certain parasite species (MacIntosh et al., 2012).

Other factors like sex and social rank also influence host exposure and susceptibility to parasites, notably because these traits might influence the frequency, quality and quantity of interactions with social partners and with the environment, e.g., when young males disperse from their natal group. These traits might also be linked to variation in physiological and immunological responses. For example, it seems that male vertebrates generally exhibit lower innate and acquired immune responses than females, 
leading to higher prevalence and intensity of parasite infection among males (Klein et al., 2004). Another case in point concerns dominance status: meta-analyses in vertebrates suggest that greater parasitism is biased toward high-ranking individuals (Habig et al., 2018). This may be linked to stressful social situations - in this case, the struggle to achieve high dominance status - that trigger the production of glucocorticoids, which then interfere with the activity of other factors essential in the activation of the immune response (Cain and Cidlowski, 2017). At the same time, if high dominance rank also confers high social capital and a central position within the group's social network (Sueur et al., 2011), then increased exposure to parasites might also explain such results (MacIntosh et al., 2012).

Another important factor for exposure and susceptibility is the host's age. The age-infection relationship is often described through three theoretical models: linear, asymptotic or convex with increasing age (Wilson et al., 2002). Each predicts that adults have different - usually lower - infection intensities than juveniles. A number of mechanisms have been uncovered that explain this phenomenon, from parasite-induced host mortality (Rousset et al., 1996), to acquired immunity (Woolhouse, 1998) or agerelated differences in exposure and susceptibility to (Izhar and Ben-Ami, 2015), or tolerance of (Jackson et al., 2014), infection. Acquired immunity in particular might be an important source of variation in infection. In general, juveniles are thought to have a less efficient or weaker immune system than adults, making them less resistant to infection (East et al., 2008; Ebersole et al., 2008; Fallon et al., 2003). Similarly, juveniles may have a higher chance of contacting infectious agents because of their specific activity patterns (e.g., greater and more diverse exploration of substrates, heightened reliance on social interactions, etc.) (Sarabian et al., 2018b). Thus, theoretically, juveniles should play an important role in the transmission dynamics of parasites. 
Often, though, studies investigating links between sociality and parasitism only include adults, perhaps because conducting research on juveniles is more difficult due to more challenging identification and observation conditions. Previous studies, including those by some of us (Duboscq et al., 2016; MacIntosh et al., 2012; Romano et al., 2016), are missing juveniles, a key group of individuals, which may preclude a fuller understanding of infection dynamics. Although unrelated to infection, a previous study using knockout simulations indicated that juvenile or adolescent baboons can act as bridges between clusters of otherwise weakly connected individuals, thus changing the nature of the networks being observed (Fedurek and Lehmann, 2017).

More generally, problems of missing data in social networks are well known: missing nodes (Kossinets, 2006; Smith and Moody, 2013), especially missing central nodes (Smith et al., 2017), produce measurement bias in social network centrality because network data are relational and hence one data point (node, edge, etc) is not independent of another. Although many network measures can be estimated with incomplete information, being robust to missing individuals (Borgatti et al., 2006), it is important to assess the impact on precision, accuracy and bias (all more or less assessed via comparing, correlating or regressing original whole-network measures with newly calculated partial-network measures) created by subsampling networks or by carrying analyses with partial networks (Silk, 2018; Silk et al., 2015). At present, we are starting to better understand the effects of using partial or subsampled networks on network measures (Smith et al. 2017; Silk et al. 2015), but we have scarce knowledge about the influence that such measurement bias has on the conclusions we might draw concerning the relationship between network characteristics and other social or ecological processes (but see Silk et al. 2015). Assessing measurement bias can thus inform us about how best to carry out our observations or even how we might correct for sampling bias when data have already been collected (Hoppitt and Farine, 
2018; Silk et al., 2015; Smith et al., 2017). It is thus meaningful to assess how including (or excluding) juveniles or any other often-missing subgroup(s), or even individuals at random, might affect our interpretation of the relationship between infection and social network centrality, which is the target of this manuscript.

Taking all of this into account, the present study examined gastrointestinal nematode parasites infecting Japanese macaques (Macaca fuscata) on Koshima island, Japan, to test: (1) whether social network centrality, as measured by the number of partners (degree), frequency of interactions (strength) and level of social integration (eigenvector) observed across individuals, was linked to an estimate of intestinal parasite infection intensity (eggs per gram of feces, EPG); and, (2) to what extent excluding portions of individuals within a group from the analyses might influence the observed relationship. Japanese macaques and their gastrointestinal parasites comprise an ideal model system for studying pathogen transmission in wildlife (MacIntosh, 2014). Japanese macaque populations are generally stable and distributed throughout Japan, have been subject to a long history of research, which provides a firm foundation regarding their ecology and social structure, and they are mainly terrestrial, enabling direct observation of social behaviour and sampling for parasitological analyses. Japanese macaques are also infected by numerous gastrointestinal nematode parasites, including various geohelminths, which are amenable to study through faecal sampling. Helminths are commonly found in mammals (Stephens et al., 2017) and can impact host health and fitness by imposing nutritional constraints and other physiological conditions that can reduce host fitness, and in some cases may directly cause mortality (Hillegass et al., 2010).

There are three known geohelminths in Japanese macaques: Oesophagostomum aculeatum (Strongylida), Strongyloides fuelleborni (Rhabditida) and Trichuris trichiura (Trichocephalida) (Gotoh, 2000). 
These parasites are transmitted through contact with contaminated substrates, though while O. aculeatum and T. trichiura use the faecal-oral pathway, S. fuelleborni infects hosts percutaneously. Voided with feces, the eggs of O.aculeatem and S. Fuelleborni hatch and develop into infectious third-stage larvae in the environment. S. Fuelleborni exhibits a heterogonic life cycle whereby some larvae continue to develop in the external environment and persist as free-living adults, mating and reproducing opportunistically. Others (females only) become parasitic in a host. In contrast, the eggs of $T$. trichiura become embryonated but do not hatch until they have been ingested by a suitable host. Each can thus be transmitted between hosts that share environmental resources, even if separated in time (Modrý et al., 2018). So, in this study, we assumed that the transmission of parasites is linked with space sharing, which is reflected in patterns of spatial proximity among individuals within a network.

We tested for a relationship between centrality and infection in our empirical data set, and then used targeted pseudo-random knock-out simulations of specific age classes of individuals, as well as random knock-out simulations of specific proportions of individuals, for comparison with the original results. We made a number of predictions. First, we predicted a positive association between an individual's social network centrality and its gastrointestinal nematode parasite infection intensity (estimated via faecal egg counts), as was found previously in Japanese macaques (MacIntosh et al., 2012). Second, we predicted that taking into account only partial networks might lead to divergent results concerning the network-infection link. Partial networks examined included a juvenile-only network, because of their high rates of infection (MacIntosh et al., 2010), an adult female-only network, because of their core role in macaque society, and a series of random subsets of the network. We do not make more precise predictions here as we cannot a priori predict with confidence the effects of missing individuals on network measures. 


\section{Methods}

Ethical Statement

The research presented here complied with the Guidelines for the Care and Use of Nonhuman Primates established by the Primate Research Institute of Kyoto University (KUPRI), to the legal requirements of Japan and to the American Society of Primatologists (ASP) Principles for the Ethical Treatment of Non-Human Primates. Permissions were acquired from the Field Research Committee of KUPRI, the Cooperative Research Program of the Wildlife Research Center of Kyoto University, and the City of Kushima Agency for Cultural Affairs.

Study site and subjects

This research was conducted on Koshima island, a $0.35 \mathrm{~km}^{2}$ island located in the Sea of Hyūga in Miyazaki Prefecture, Japan $\left(31^{\circ} 27^{\prime} \mathrm{N}, 131^{\circ} 22^{\prime} \mathrm{E}\right)$. The island is inhabited by two groups of monkeys and some solitary males. The study group, the "main" group, inhabits the western part of the island, including a sandy beach, a range of forest and a rim of rocky beach. Provisioning and behavioural observations of Koshima macaques started in 1952, and demographic, ecological, behavioural and lifehistory data are available since then (Watanabe, 2008). Previous studies on this island identified four nematode parasites infecting Koshima macaques (Gotoh, 2000; Horii et al., 1982). The study group is currently provisioned with approximately $3 \mathrm{~kg}$ of wheat twice weekly. At the time of the study, the main group had 47 stable group members and 5 solitary roaming males that ranged in proximity of the group on an irregular basis. The group included 20 adult females ( $\geq 5$ years old), 8 adult males ( $\geq 5$ yo) (including the 5 solitary males), 13 juvenile females (between 1 and 4 yo) and 11 juvenile males (between 1 and 4 yo). Because the population has been monitored for decades, we have the exact ages of each individual in the population. 


\section{Behavioural Data Collection}

The observation team - including ZX, AC-N, EM-M - observed the monkeys for 88 days over 3 months from March to June 2017. All individuals could be identified reliably based on a combination of facial and other physical characteristics (such as facial tattoos, scars, limps, coat colour, etc.), and allowed researchers to approach within $5 \mathrm{~m}$, facilitating observation and faecal sample collection. We carried out 20-minute focal animal observations, recording behavioural activities of the focal individual (including resting, feeding, locomotion, playing, giving and receiving grooming, and self-grooming) at 30-second intervals. At the same scan point, we also recorded the identity of each individual within $1 \mathrm{~m}$ of, or in body contact with, the focal animal. Agonistic interactions of all individuals in the group were recorded ad libitum. To assess the dominance hierarchy, we used all agonistic interactions recorded by the observation team between November 2016 and June 2017. We observed every individual in the group, including two infants that were born in 2016, every day in a pseudorandomized order, updated daily. We avoided repeating observations of the same individual on the same day, and we balanced observations between individuals as much as possible across days and times of day (e.g., early and late morning, early and late afternoon). Data were collected either on paper or using a tablet (Panasonic Tough-pad, with the application PRIM8 (McDonald and Johnson, 2014)). A multi-observer reliability test based on Fleiss' Kappa index was conducted (Fleiss and Cohen, 1973). Observers had a Kappa index of 0.815 for proximity records including the identities of all subjects involved. In total, we conducted 547 focal observations recording 22,066 focal scans, or 183.3 hours of focal observations, with a mean \pm SD of $10.7 \pm 6.6$ focal follows per individual. Table S1 in the Supplementary material summarizes the attributes of and data from the study subjects. 


\section{Social data analysis}

\section{Dominance}

To compute the dominance rank of all individuals, we used the Elo-rating method (Neumann and Kulik, 2014), which reflects an individual's success in agonistic interactions relative to all other members (Albers and de Vries, 2001; Neumann et al., 2011). Elo-rating is based on a sequence of agonistic interactions ordered in time. Each individual is seeded with an arbitrary rating of 1000. This rating is then updated after each agonistic interaction with a clear outcome. The rating increases/decreases based on the outcome of the interaction (won or lost), the previous ratings of both opponents and a determined factor, $\mathrm{k}$ (here $\mathrm{k}=100$ (Neumann et al., 2011)). In our analyses, we used the Elo-ratings for all individuals at the end of the observation period.

\section{Social network centrality}

We constructed an undirected proximity network based on recorded $1 \mathrm{~m}$ (close) proximity. We built a symmetrical matrix of undirected social proximities, in which dyadic proximity data were scaled by the number of scans collected from each individual of the corresponding dyad. The proximity matrix was then analysed with the package "igraph" (Csardi and Nepusz, 2006) in R Statistical Software v.3.5.3 (R Development Core Team, 2019). For each individual, we computed: (1) degree (how many partners an individual has); (2) strength (how many times an individual was in proximity with others); and, (3) eigenvector (the sum of the centralities of an individual's neighbours; high centrality can be achieved by having either a large degree or being connected to associates with a high degree (or both) (Farine and Whitehead, 2015)). 


\section{Parasite Collection and Analysis}

We opportunistically collected between 1 and 4 fresh faecal samples per individual ( $3.5 \pm 1.6)$ during observations whenever a clearly identified individual was seen defecating. We put the entire faeces into a sealable plastic bag and into a cooler bag with ice until we brought all samples to the lab for processing. Within $12 \mathrm{~h}$ of collection, we weighed and homogenized about 1-2 grams of faeces into $3.5 \mathrm{ml}$ of a sodium acetate-acetic acid-formaldehyde (SAF) solution for preservation of parasite eggs and larvae. After the fieldwork period, we sent all samples to Kyoto University's Primate Research Institute for further analysis.

We processed all parasitological samples following previous work with Japanese macaque parasites using a modified formalin-ethyl acetate sedimentation protocol to concentrate helminth eggs from faeces (MacIntosh et al., 2010). We added 5 drops of Triton X-100 to the faecal mixture before filtration to better isolate eggs from other components of faeces. To filter samples, we used a $330 \mu \mathrm{m}$ Saran $^{\mathrm{TM}}$ mesh (Asahi Kasei, Japan). To reduce the amount of formaldehyde consumed in the process, we used saline instead of formaldehyde for all intermediate washing steps during concentration. For all centrifugation steps, we spun our samples at 3000 rpm for 5 minutes.

After processing, we again suspended the retained faecal pellet in SAF and stored it at room temperature until analysis. For parasitological examination, we used a volumetric method based on McMaster microscopy to estimate the intensity of parasitic infection in each individual through counting the number of eggs observed per gram of faecal sediment (EPG) (Modrý et al., 2018). We drew aliquots from the faecal suspension, kept homogeneous during reading using a magnetic stirrer, and viewed them in a McMaster chamber with a 10x objective lens. Parasite eggs were identified by their specific morphology and size (Modrý et al., 2018). We repeated this procedure five times per sample and used the 
mean count to calculate EPG from each sample based on the amount of sediment viewed per volume of suspension, with the following formula:

$$
\mathrm{EPG}=\frac{\frac{\text { total number of eggs }}{\text { number of chambers }}}{\frac{W_{\text {sediment }}}{V_{\text {solution }}} \times V_{\text {chamber }}}
$$

In the formula, total number of eggs reflects the number of eggs the examiner counted in all chambers. The number of chambers refers to the number of chambers examined in the sample (here, 5). $W_{\text {sediment }}$ refers to the weight of the faecal pellet after filtration, and $V_{\text {solution }}$ refers to the volume of solution that was used to dilute the sample (in this case, between $10 \mathrm{ml}$ and $50 \mathrm{ml}$ depending on thickness of the faecal suspension, which significantly affects viewing). $V_{\text {chamber }}$ refers to the volume of suspension contained in each counting chamber $(0.15 \mathrm{ml}$ for a single McMaster chamber). EPG is a standard index of parasite infection intensity and, although it is not always indicative of true worm infection intensity (Gillespie, 2006; Modrý et al., 2018), it is commonly used in wildlife parasitology, particularly in cases where parasite population estimation is needed but it is neither advisable nor possible to sample individuals via other - more invasive - means.

\section{Statistical Analyses}

All statistical analyses were conducted using R v3.5.3 (R Development Core Team, 2019). We built a dataset that included one line for each parasite species in each faecal sample as the unit of analysis, i.e., three times (three parasite species) the number of faecal samples analysed. In addition, each sample was associated with an individual and all of its attributes, including its centrality measures (degree, strength, and eigenvector), Elo-rating, sex and age, along with the sample's collection date. EPG was used as the response variable in the statistical models described below. The dataset (SP 1) and scripts 
bioRxiv preprint doi: https://doi.org/10.1101/2021.06.07.447302; this version posted June 20, 2021. The copyright holder for this preprint (which was not certified by peer review) is the author/funder, who has granted bioRxiv a license to display the preprint in perpetuity. It is made available under aCC-BY-NC-ND 4.0 International license.

are available on Git repository: https://github.com/XuZhihong-cn/Network_Centrality_analysis_and_KOsimulation

\section{Testing for associations between network centrality and parasite infection intensity}

We modelled EPG as zero-inflated and overdispersed count data. Parasites typically exhibit an aggregated distribution across their hosts that is best approximated by the negative binomial distribution (Crofton, 1971; Poulin, 2007; Shaw et al., 1998). We confirmed that our EPG-distribution indeed followed a negative binominal distribution using the fitdistr function from the R package "MASS" (Venables and Ripley, 2002). We then built generalized linear mixed models with a negative binomial error structure using the "glmmTMB" package (Brooks et al., 2017). Since the three centrality measures we investigated are related to each other in our data (Pearson's Correlation of degree and strength: $r=$ $0.49, \mathrm{p}<0.001$; degree and eigenvector: $\mathrm{r}=0.33, \mathrm{p}<0.05$; strength and eigenvector: $\mathrm{r}=0.76, \mathrm{p}<0.001$ ), and since eigenvector is itself derivative of degree and strength, including them in the same model would violate the assumption of data independence (Webber et al., 2020), so we constructed one model for each one of them and used model averaging via the function "model.avg" in the R package MuMIn (Barton, 2018) to estimate the coefficients for variables appearing in more than one model (i.e., sex, age, and Elo-rating). Given that we collected multiple feacal samples per individual and that EPG can vary considerably over time and sample to sample within an individual (Wood et al., 2013), we set the individual ID and date of sample collection as random effects in the models. Because EPG varies considerably across parasite species, and because exploring mean differences between parasite species was not the focus of this study, we set parasite species as an additional random effect in the models. 
The model residuals showed heteroscedasticity and overdispersion, so we added a zero-inflation term to account for the substantial number of zeros in the EPG data (124 instances or $24 \%$ of the 517 total data points). The zero-inflated models showed better residual distributions and significantly lower AIC compared with standard negative binomial models (for the degree models, AIC of zero-inflated model is 7268.8 while AIC of the simple model is 7727.0 ; for the strength models, AIC is 7254.5 compared with 7718.0; for the eigenvector models, AIC is 7260.7 compared with 7722.1). We also assessed whether other assumptions of the models were met, such as lack of multicollinearity (variance inflation factor $<3$ ) and overly influential cases (Cook's distance $<4 / \mathrm{N}$ ). Lastly, we conducted likelihood ratio tests to evaluate the statistical strength of our models against an informed null model containing only the control factors age, sex, and Elo-rating, and complete set of random effects.

\section{Testing the significance of the effect of centrality on parasite infection intensity}

Centrality measures are not independent because they are derived from a network where all individuals are linked to one another. This non-independence violates many assumptions from most statistical tests. A robust and standard way to consider this issue is to compare statistical models based on the original observed data to a distribution of null models based on randomized data (Farine, 2017). In this study, we randomized networks using the function rewire of the package "igraph" (Csardi and Nepusz, 2006) and a probability of rebuilding a connection randomly chosen between 0 and 1 to account for nonrandom partner choice. We used edge rearrangement to get a null model that randomly rearranges the observed interactions among pairs of nodes because we were confident in the observed edges (Croft et al., 2011). After each randomization, centrality measures were re-calculated and re-integrated in the statistical models (the same models as before but with the network measure derived from randomization). 
After 1000 randomizations, the statistical parameters of interest (here, model estimates) were compared between models based on observed data and "null" models based on randomized data. If a substantial proportion $(95 \%)$ of statistical parameters derived from models based on observed data were lower/higher than parameters derived from models based on randomized data, then we could conclude that the observed effects of sociality on parasitism were different from those expected to arise by chance (Duboscq et al., 2016; Farine, 2017). The randomization procedure was identical for all models.

Testing the effect of knockout simulations on the relationship between centrality and parasite infection intensity

To have a point of comparison with previous studies and to gain insight into the influence of only examining certain age-sex classes on the relationship between centrality and infection intensity, we ran two more analyses. We first constructed partial social networks including only (1) adult females, which was done in our previous studies, or (2) juveniles, to test the strength of the sociality-parasitism relationship in a rarely investigated age-class. To compare the network metrics from original and partial networks, we calculated the Pearson's correlation coefficient between the original and partial network metrics. Then, we built models with the same structure as those described above but with network metrics calculated from partial networks. These models went through all the checks as previously described. Removing individuals from the network itself might already affect social network structure and thus change the observed result. In a second step, therefore, we conducted randomized knock-out simulations: we randomly removed $5 \%, 10 \%, 25 \%$ and $50 \%$ of individuals from the network, re-calculated the network metrics and re-integrated them into the models for calculation over 1000 iterations. After each simulation, the model parameters of interest (here estimates and confidence intervals) were saved and the results were compared with the results from the original models. We chose those percentages because 
bioRxiv preprint doi: https://doi.org/10.1101/2021.06.07.447302; this version posted June 20, 2021. The copyright holder for this preprint (which was not certified by peer review) is the author/funder, who has granted bioRxiv a license to display the preprint in perpetuity. It is made available under aCC-BY-NC-ND 4.0 International license.

they represent biologically relevant cases of missing individuals during data collection or within a study design, like solitary roaming males or peripheral females (e.g., $<10 \%$ of the group), or when taking into account only certain age-sex classes, here adult females or juveniles, effectively removing everyone else (e.g., $>25 \%$ of the group, depending on group composition and demography).

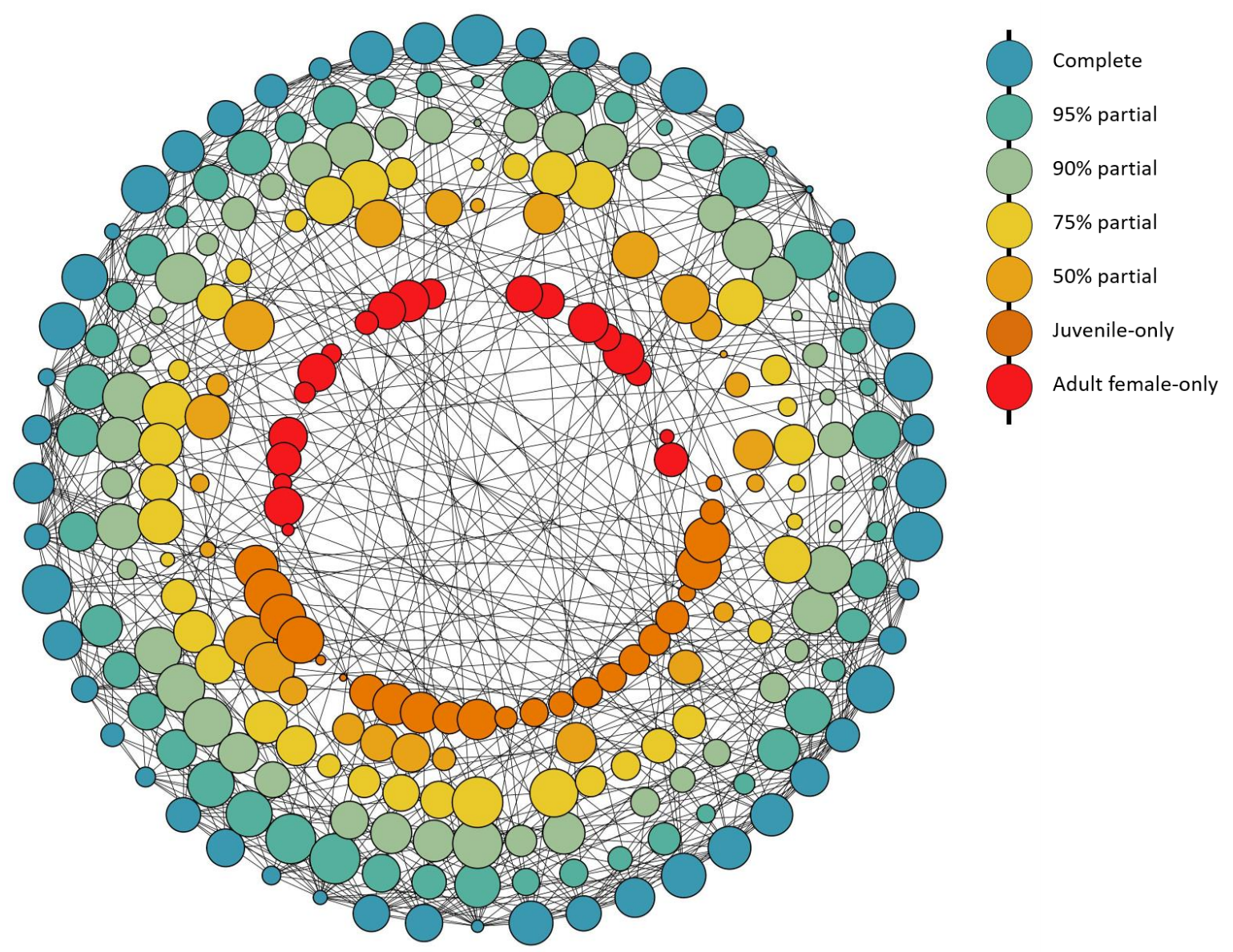

Figure 1: Network graph representing differences in each individual's eigenvector centrality in complete networks versus partial networks. All the edges are based on the complete network. Node size represents the eigenvector rank of each individual in the network; larger nodes have higher eigenvector rank. To make nodes comparable across networks, we also removed the rank values that each node held in the complete network when removing them from the partial networks so that change of node size remains consistent across networks even when fewer individuals are included. 


\section{Results}

Social network metrics

Across the observation period, we found that the average \pm SD degree centrality of the 52 individuals in the study group was $13.80 \pm 5.48$, the average strength centrality was $0.44 \pm 0.21$, and the average eigenvector centrality was $0.32 \pm 0.29$. When considering only adult females, the same values were 13.75 $\pm 4.22,0.55 \pm 0.20$, and $0.39 \pm 0.32$, respectively. In the juvenile-only network, these values were $15.33 \pm$ $4.93,0.43 \pm 0.16$, and $0.33 \pm 0.32$, respectively.

Parasitological results

We observed four nematode parasites infecting our subjects during the study period: Oesophagostomum aculeatum, Strongyloides fuelleborni, Trichuris trichiura and Streptopharagus pigmentatus. Concerning the geohelminths only, O. aculeatum, S. fuelleborni and T. trichiura - which were the focus of this study - most of the individuals were infected by all parasites. Juveniles showed the highest average EPG compared to the average group-level EPG and that of adult females only (Table 1).

Table 1. Summary of prevalence and infection intensity (EPG) of three geohelminths examined in this study.

O. aculeatum T.trichiura S.fuelleborni.

\begin{tabular}{clcccc}
\hline \multirow{2}{*}{ Full group data } & Prevalence & $100 \%$ & $90 \%$ & $90 \%$ \\
\cline { 2 - 5 } & Average EPG & $1380.72 \pm 863.28$ & $775.09 \pm 989.16$ & $3080.10 \pm 3776.99$ \\
\cline { 2 - 5 } Adult females only & Prevalence & $100 \%$ & $90 \%$ & $85 \%$ \\
\cline { 2 - 5 } & Average EPG & $1172.38 \pm 578.25$ & $345.21 \pm 383.47$ & $682.33 \pm 918.725$ \\
\cline { 2 - 4 } & Prevalence & $100 \%$ & $96 \%$ & $100 \%$ \\
& Average EPG & $1736.90 \pm 975.41$ & $1282.26 \pm 1195.90$ & $5827.03 \pm 3811.14$
\end{tabular}




\section{Network-infection relationship}

\section{Complete networks}

Likelihood ratio tests demonstrated that the full models with strength and eigenvector centrality but not with degree centrality had higher explanatory value than their respective informed null models (Table 2). Randomizations (Table 2, SP 2) further demonstrated that strength and marginally eigenvector but not degree centralities were related to infection intensity in a way that differed from that expected by chance: the strength model showed observed estimates higher than randomised estimates in $99.7 \%$ of all randomisations, meaning the relationship it tested was "significantly" not likely to occur by chance (for the degree model, $86.6 \%$ of estimates were higher than those generated with randomised data; for the eigenvector model, 90.4\%).

Strength and eigenvector centralities were positively related to infection intensity, such that more central individuals had higher EPG of intestinal nematodes (Table 2). Age was negatively related to infection: the younger the individual the more likely it was to show high EPG. Sex and dominance rank were overall not related to infection intensity (Figure 2). 

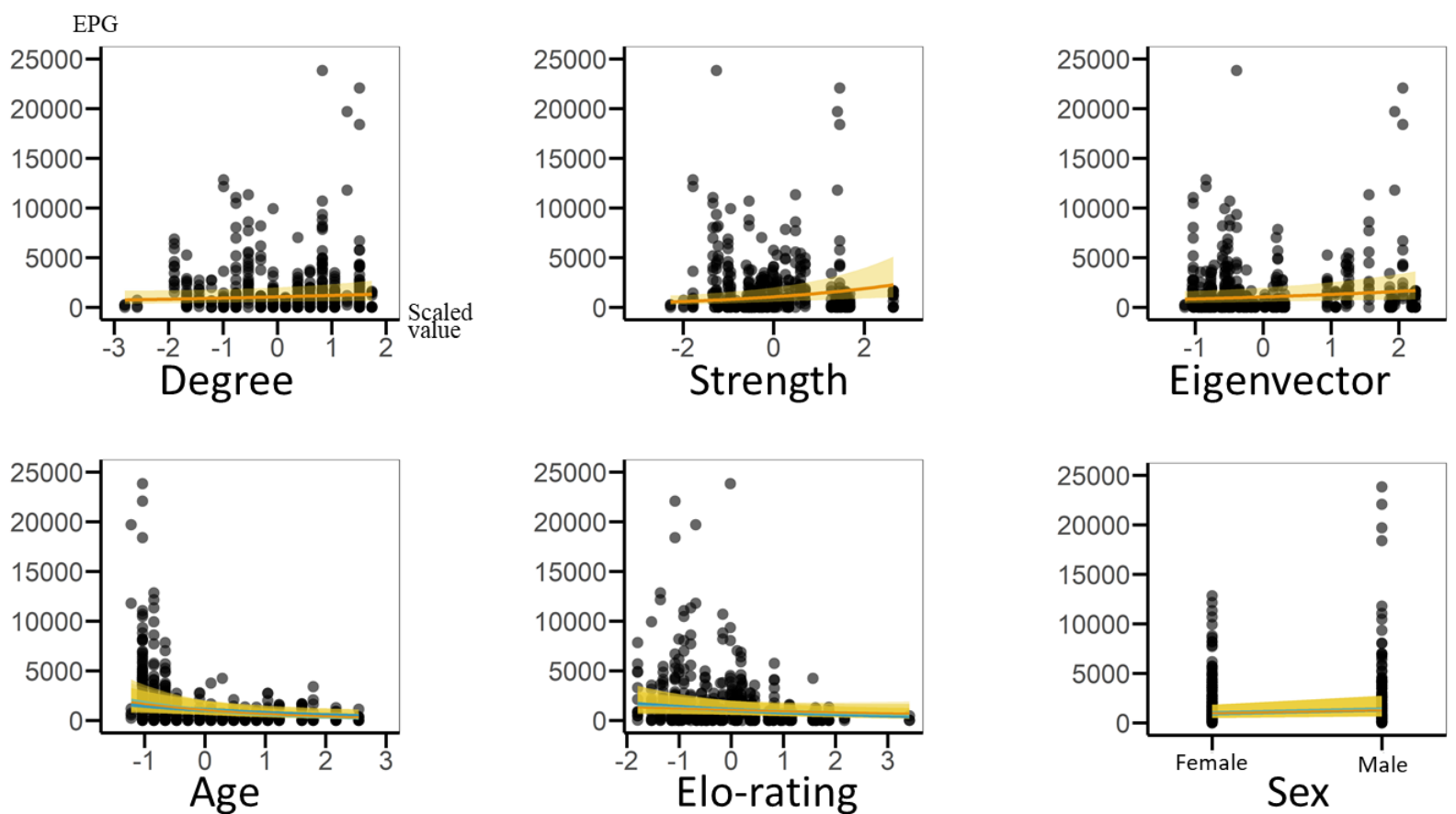

Figure 2: Regression plots representing results of GLMMs based on the complete network. All fixed factors are scaled and centred. Since we constructed three different models for each network metric, the regression plots representing shared factors (age, Elo-rating and sex) show lines from each of the models in different colours.

Table 2. Results of GLMMs testing for variation in geohelminths infection intensity (EPG) among Japanese macaques on Koshima island. Estimates $\beta$ are given with standard errors SE and p-value p; LRT are likelihood ratio tests, here with $\chi^{2}$ tests, degrees of freedom d.f. and $p$-value $p$; $\Sigma\left(\beta_{\text {nb.obs.cent }}>\beta_{\text {nb.rand.cent }}\right) /$ nb.rand gives the number of times the estimate $\beta$ of network measures from the model based on original observed social network, nb.obs.cent, are higher than the estimate of network measures from the model based on randomized social network nb.rand.cent divided by the number of randomizations nb.rand. (see main text), in bold when $>0.95$.

\begin{tabular}{|c|c|c|c|}
\hline Variables & $\begin{array}{c}\text { Estimate } \beta \pm \mathrm{SE} \\
{[\mathrm{p}]}\end{array}$ & $\begin{array}{l}\text { LRT full vs. null } \\
\qquad\left(\chi^{2} ; \text { d.f.; } p\right)\end{array}$ & $\begin{array}{l}\Sigma(\beta \text {-nb.obs.cent }<\beta \text { - } \\
\text { nb.rand.cent }) / n b . \text { rand. }\end{array}$ \\
\hline Intercept & $\begin{array}{c}6.88 \pm 0.33 \\
{[<0.001]}\end{array}$ & I & l \\
\hline Degree & $\begin{array}{c}0.12 \pm 0.09 \\
{[0.169]}\end{array}$ & $1.908 ; 2 ; 0.3852$ & 0.866 \\
\hline Strength & $\begin{array}{c}0.29 \pm 0.10 \\
{[0.003]}\end{array}$ & $16.230 ; 2 ;<0.001$ & 0.997 \\
\hline Eigenvector & $\begin{array}{c}0.21 \pm 0.09 \\
{[0.027]}\end{array}$ & $10.059 ; 2 ; 0.007$ & 0.904 \\
\hline Age & $\begin{array}{c}-0.53 \pm 0.13 \\
{[<0.001]}\end{array}$ & I & I \\
\hline Sex (male) & $\begin{array}{c}0.33 \pm 0.22 \\
{[0.125]}\end{array}$ & I & I \\
\hline Elo-rating & $\begin{array}{c}-0.15 \pm 0.11 \\
{[0.164]}\end{array}$ & I & I \\
\hline
\end{tabular}




\section{Female- and juvenile-only networks}

When comparing measures calculated from partial versus whole networks, in both female-only and juvenile-only networks, partial-network measures were well to moderately correlated with the original whole-group-network measures (females: $\mathrm{r}_{\text {degree }}=0.79, p<0.001, \mathrm{r}_{\text {strength }}=0.38, p<0.100, \mathrm{r}_{\text {eigenvector }}=$ 0.63, $p<0.010$; juveniles: $\left.\mathrm{r}_{\text {degree }}=0.90, p<0.001, \mathrm{r}_{\text {strength }}=0.65, p<0.001, \mathrm{r}_{\text {eigenvector }}=0.54, p<0.010\right)$.

Using data from adult females only, likelihood ratio tests demonstrated that the full models with strength, but not those with eigenvector or degree centrality, had higher explanatory value than their respective informed null models (Table 3). Randomizations (Table 3, SP 2) further demonstrated that among adult females, network centralities were not related to infection intensity in a way that differed from that expected by chance (strength model: observed estimates higher than randomised estimates in 85.6\% of all randomisations; degree model, $76.5 \%$; eigenvector model: $77.4 \%$.). Age and social rank were unrelated to nematode infection intensity (SP 3).

Using data from juveniles only, likelihood ratio tests demonstrated that none of the full models had higher explanatory value than their respective informed null models (Table 4). Randomizations (Table 4, SP 2) further demonstrated that network centralities were not related to infection intensity in a way that differed from that expected by chance (degree model: observed estimates higher than randomised estimates in $54.2 \%$ of all randomisations, strength model: $68.5 \%$; eigenvector model: $67.4 \%$.). Among juveniles only, age was negatively associated with infection: the younger the individual the more likely it was to show higher EPG. We also found that a juvenile's sex was associated with its infection intensity, with juvenile males showing higher EPG than juvenile females (SP 4). 
bioRxiv preprint doi: https://doi.org/10.1101/2021.06.07.447302; this version posted June 20,2021 . The copyright holder for this preprint (which was not certified by peer review) is the author/funder, who has granted bioRxiv a license to display the preprint in perpetuity. It is made available under aCC-BY-NC-ND 4.0 International license.

Table 3. Results of GLMMs based on adult females testing for variation in geohelminths infection intensity (EPG) among Japanese macaques on Koshima island. Estimates $\beta$ are given with standard errors SE and p-value p; LRT are likelihood ratio tests, here with $\chi^{2}$ tests, degrees of freedom d.f. and $p$-value p; $\Sigma\left(\beta_{\text {nb.obs.cent }}>\beta_{\text {nb.rand.cent }}\right) /$ nb.rand gives the number of times the estimate $\beta$ of network measures from the model based on original observed social network, nb.obs.cent, are higher than the estimate of network measures from the model based on randomized social network nb.rand.cent divided by the number of randomizations nb.rand. (see main text), in bold when $>0.95$.

\begin{tabular}{|c|c|c|c|}
\hline Variables & $\begin{array}{c}\text { Estimate } \beta \pm \mathrm{SE} \\
{[\mathrm{p}]}\end{array}$ & $\begin{array}{l}\text { LRT full vs. null } \\
\qquad\left(\chi^{2} ; \text { d.f.; } p\right)\end{array}$ & $\begin{array}{c}\Sigma(\beta \text {-nb.obs.cent }<\beta \text { - } \\
\text { nb.rand.cent }) / \text { nb.rand. }\end{array}$ \\
\hline Intercept & $\begin{array}{c}6.88 \pm 0.33 \\
{[<0.001]}\end{array}$ & 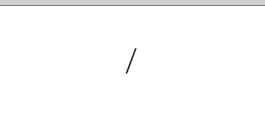 & 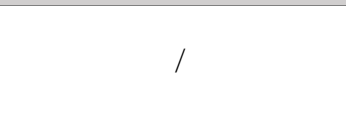 \\
\hline Degree & $\begin{array}{c}0.25 \pm 0.13 \\
{[0.053]}\end{array}$ & $3.380 ; 2 ; 0.1845$ & 0.765 \\
\hline Strength & $\begin{array}{c}0.32 \pm 0.12 \\
{[0.008]}\end{array}$ & $7.014 ; 2 ; 0.03$ & 0.856 \\
\hline Eigenvector & $\begin{array}{c}0.26 \pm 0.13 \\
{[0.043]}\end{array}$ & $3.942 ; 2 ; 0.1393$ & 0.774 \\
\hline Age & $\begin{array}{c}-0.08 \pm 0.14 \\
{[0.565]}\end{array}$ & I & I \\
\hline Elo-rating & $\begin{array}{c}-0.07 \pm 0.14 \\
{[0.632]}\end{array}$ & I & I \\
\hline
\end{tabular}

Table 4. Results of GLMMs based on juveniles testing for variation in geohelminths infection intensity (EPG) among Japanese macaques on Koshima island. Estimates $\beta$ are given with standard errors SE and $\mathrm{p}$-value p; LRT are likelihood ratio tests, here with $\chi^{2}$ tests, degrees of freedom d.f. and $\mathrm{p}$-value $\mathrm{p}$; $\Sigma\left(\beta_{\text {nb.obs.cent }}>\beta_{\text {nb.rand.cent }}\right) /$ nb.rand gives the number of times the estimate $\beta$ of network measures from the model based on original observed social network, nb.obs.cent, are higher than the estimate of network measures from the model based on randomized social network nb.rand.cent divided by the number of randomizations nb.rand. (see main text), in bold when $>0.95$.

\begin{tabular}{|c|c|c|c|}
\hline Variables & $\begin{array}{c}\text { Estimate } \beta \pm \mathrm{SE} \\
{[\mathrm{p}]}\end{array}$ & $\begin{array}{l}\text { LRT full vs. null } \\
\qquad\left(\chi^{2} ; \text { d.f.; } p\right)\end{array}$ & $\begin{array}{c}\Sigma(\beta \text {-nb.obs.cent }<\beta- \\
\text { nb.rand.cent }) / n b . r a n d\end{array}$ \\
\hline Intercept & $\begin{array}{c}6.88 \pm 0.33 \\
{[<0.001]}\end{array}$ & l & l \\
\hline Degree & $\begin{array}{c}0.03 \pm 0.10 \\
{[0.769]}\end{array}$ & $0.112 ; 2 ; 0.9454$ & 0.542 \\
\hline Strength & $\begin{array}{c}0.12 \pm 0.09 \\
{[0.182]}\end{array}$ & $2.353 ; 2 ; 0.3084$ & 0.685 \\
\hline Eigenvector & $\begin{array}{c}0.12 \pm 0.11 \\
{[0.268]}\end{array}$ & $1.57 ; 2 ; 0.456$ & 0.904 \\
\hline Age & $\begin{array}{c}-0.39 \pm 0.10 \\
{[<0.001]}\end{array}$ & l & 1 \\
\hline Sex (male) & $\begin{array}{c}0.46 \pm 0.20 \\
{[0.021]}\end{array}$ & l & I \\
\hline Elo-rating & $\begin{array}{c}-0.10 \pm 0.11 \\
{[0.355]}\end{array}$ & l & l \\
\hline
\end{tabular}




\section{Random partial networks}

Concerning analyses with partial networks, where portions of individuals were randomly knockedout, we focused only on models with strength and eigenvector centralities because these had more weight in explaining the data than did models with degree (see above). Random removals of individuals comprising 5, 10, 25 and 50\% of the group all led to the elimination of the observed relationship between infection and centrality (Table 5, SP 5), i.e., the observed relationship estimates approached zero and model comparisons did not indicate statistical significance.

Table 5: Results of 1000 random removals of individuals (\% given in first column) run with observed network data and used to (re)model the relationship between network centrality (here strength or eigenvector) and infection intensity. The heading "Number of model results equivalent to observed" indicates the number of simulation model results out of 1000 simulations that gave a positive estimate for the relationship between centrality and EPG within a 95\% confidence interval excluding zero (see text for details).

\begin{tabular}{|ccc|}
\hline $\begin{array}{c}\text { Centrality } \\
\text { measure }\end{array}$ & $\begin{array}{c}\text { Percentage of } \\
\text { individuals removed }\end{array}$ & $\begin{array}{c}\text { Number of model results } \\
\text { equivalent to observed }\end{array}$ \\
\hline Degree & 5 & 10 \\
& 10 & 28 \\
Strength & 25 & 46 \\
& 50 & 36 \\
& 5 & 75 \\
& 10 & 59 \\
& 25 & 32 \\
\hline
\end{tabular}

\section{Discussion}

Studies have shown repeatedly that increased sociality is linked to increased parasitism (Godfrey, 2013; Nunn, 2012; Rushmore et al., 2017; White et al., 2017), constituting a major cost of group living. However, not all kinds of social investment are equivalent in terms of parasite transmission: sometimes it is having a lot of social partners, or living in a big group, that leads to increased infection (Böhm et al., 2009; Weber et al., 2013), while at other times specific properties of an individual's position within 
a network may mediate this relationship. Our results reflect the latter case, in that we showed positive correlations between geohelminth infection intensity and two out of three social network centralities examined (strength and eigenvector but not degree) in a Japanese macaque group. In brief, the frequency with which individuals were in proximity to one another and their further social integration, but not the number of individuals with which they shared proximity, were positively associated with infection intensity of geohelminths. Moreover, we demonstrated that the choice of animals within a study group (i.e., sampling bias) can impact the relationship that is observed between network centrality and parasitism, a fact that is often neglected or ignored in wildlife studies. Incomplete networks - e.g., those including only a subset of the group like adult females or juveniles - yielded divergent results compared to those analyses that included the whole-group network, with the statistical relationship originally observed between network centrality and infection intensity disappeared. From an epidemiological perspective, every individual can be responsible for the transmission of pathogens, so that neglecting them in the analysis may affect the reliability of the data set. From a social network perspective, neglecting individuals can dramatically change the network structure and affect the metrics calculated (Kossinets, 2006; Silk, 2018; Silk et al., 2015; Smith and Moody, 2013; Smith et al., 2017). Thus, sampling bias can lead to misdirected conclusions about the relationships between sociality and parasitism.

The overall positive association we observed between geohelminth infection intensity and both network strength and eigenvector centrality partially aligns with the results of previous work in a different population of Japanese macaques (MacIntosh et al., 2012). As in our study, not all network metrics could predict infection intensity, but both investigations now suggest that eigenvector centrality, whether in grooming or in proximity networks, is associated with nematode parasitism in Japanese macaques. Our results also align with a recent meta-analysis of studies investigating parasites in host social networks, wherein strength and eigenvector centrality showed stronger associations with parasitism than did any of betweenness, closeness or degree centrality (Briard and Ezenwa, 2021). It therefore seems important to consider what these various centrality measures represent in terms of host socio-biology, and in terms of social or ecological processes.

In our study, strength represents how frequently individuals were in proximity to others during observations. For the parasites under consideration here, the eggs or larvae are voided in feces, meaning 
that there is a time-lag between infection of one host and transmission to the next host through the environment. Geohelminths also do not replicate within a host, meaning that EPG reflects the cumulative acquisition of each parasite over time. It thus appears reasonable for strength to be associated with infection intensity: the more often a macaque remains in proximity to others, the more resources it is likely to share with others and the more likely it is to encounter infectious stages of parasites in the environment. Such social individuals, particularly those that have spatiotemporal associations with other heavily infected individuals, experience greater risk encountering, accumulating, and transmitting parasites.

Degree centrality, on the other hand, represents how many others an individual has been in proximity with, regardless of duration, and we observed no relationship between it and geohelminth infection, here or previously (MacIntosh et al., 2012). There are some reasons not to expect such an association, for example because even individuals with the same degree score might spend very different amounts of time in proximity to other individuals. Not only does this create a heterogeneous group in terms of real social interaction, individuals with high degree but low frequencies of interaction may still lack the real spatiotemporal associations that facilitate parasite transmission. Furthermore, degree centrality may not be a good predictor of proximity to the individuals most likely to transmit infections, i.e., associations with many uninfected or lightly infected individuals may dilute infection risk (Otterstatter and Thomson, 2007; Powell et al., 2020; VanderWaal et al., 2013). Another consideration is the type of parasite under investigation. For example, it was demonstrated previously in the same group of Japanese macaques that degree centrality may at times be positively associated with estimates of louse infestation (Duboscq et al., 2016). Lice are parasites that can transmit directly between individuals over short time scales and can subsequently colonize the new host relatively quickly. In that sense, degree centrality reflects an immediate risk (Borgatti, 2005), but this is not the dominant mode of transmission for geohelminths.

Lastly among the centrality measures we investigated, eigenvector is a measure of social integration in a group through both direct and indirect connections and depends on both an individual's strength and degree, as well as that of their associates. This measure thus represents neighbourhood effects, where direct neighbours but also neighbours of neighbours can affect one's own centrality. Since geohelminths 
produce chronic infections and individuals rarely if ever become fully resistant, repeated exposure can lead to continuous reinfection with the same parasite. In such cases, eigenvector centrality may be a critical long-term risk factor for repeated parasite exposure (Borgatti, 2005). Its relationship with geohelminths might thus suggest general trends for well-connected individuals and their associates to encounter parasites at similar rates through increased interactions or use of shared space.

Having observed a positive association between social network and geohelminth infection, we then tested the impact of sampling bias on these results, by including/excluding certain age-sex classes from the analysis. For various reasons, numerous studies have focused on specific age-sex classes rather than the whole social group (Hamilton et al., 2020; Roberts and Roberts, 2020; Sandel et al., 2021; Webber et al., 2016). Through targeted removal of network subsets and subsequent reanalysis, we demonstrated that the original relationship observed using the whole group network becomes insignificant, both in classical statistical terms (i.e., loss of statistical significance) and in absolute quantitative terms, as the model parameter estimates were in some cases considerably lower, to the point where we could not conclude from randomisation tests that the observed effects of sociality on parasitism were different from those expected to arise by chance. This was true for networks including only adult females or only juveniles, although in all cases the direction of the centrality-infection link remained positive. This contrasts somewhat with a previous study that did find a significantly positive relationship between geohelminth infection and network centrality when only considering adult females in the network (MacIntosh et al., 2012). However, note that this previous study was conducted over a period of 16 months and therefore had access to a much larger data set. In the present study, the adult female network was still more predictive of infection than the juvenile network, albeit less so than the full network.

It may also be relevant to note that, in our study as in previous work with Japanese macaques (MacIntosh et al., 2010), juveniles exhibited higher infection intensities than adults. Furthermore, among juveniles, younger juveniles and males shed more parasite eggs than did older juveniles and females. These results concur with the general findings that young animals and males are disproportionately infected by parasites (Habig and Archie, 2015; Hinney et al., 2011; Khan et al., 2010). Hypotheses explaining this difference include age/sex-associated hormonal profiles (Roberts et al., 2001), variable levels of immunity (East et al., 2008; Ebersole et al., 2008; Fallon et al., 2003; Roberts et al., 2001), 
different probabilities of exposure to contaminated items (Sarabian et al., 2018a; Sarabian et al., 2018b), and differing social positions within the group (Cords et al., 2010; Grassi, 2002; Liao et al., 2018). Considering the different and often higher infection intensities in juveniles, as in adult males, neglecting them from the analysis means the statistical model is based on an incomplete and biased data set, which could lead to different results or weaker observed effects. Moreover, because individuals, as connected nodes, are not independent of one another, excluding them from the network fundamentally changes its overall structure (Fedurek and Lehmann, 2017).

As presented in our study, the network metrics calculated from both the adult female-only network and the juvenile-only network are rather well correlated with those calculated from the original network, though the correlation is not perfect and such changes had a dramatic effect on the relationship originally observed between sociality and parasitism. Among these correlations, degree and strength from the juvenile-only network were closer to those from the complete network than were the same measures from the adult female-only network. In contrast, eigenvector centralities from the adult female-only network were closer to those in the complete network than were eigenvector centralities from the juvenile-only network. These differences might simply stem from the fact that, in the studied group, the number of juveniles was higher than the number of adult females, and we know that degree and strength are usually greatly influenced by the number of individuals present. Moreover, including juveniles may significantly increase the number of contacts for females because each female may have multiple offspring. However, each juvenile is likely to interact only with a small number of adults, i.e., adult female kin, so the inclusion of adults would not add many more contacts to each juvenile. Unlike strength and degree, eigenvector centrality represents the position of an individual within its whole network of connections and is a relative value, so it may not depend as much on group size (Griffin and Nunn, 2012). Since females are known to form the core of Japanese macaque groups (Yamagiwa and Hill, 1998), it may be that their patterns of interaction dominate the emergent social network structure, such that properties of female networks linked to social integration (as in eigenvector) do not change as much with the inclusion/exclusion of other subgroups. If so, links between centrality and infection in female macaques may be robust to sampling bias, whereas networks of juveniles, which are likely to vary substantially with and without the inclusion of their maternal adult kin, may not be. An alternative explanation to our results is 
also that we cannot exclude the possibility that our study period was simply too short to detect a significant relationship between centrality and infection in subsets of the group, particularly in females. That notwithstanding, our study does show that not considering all subsets of individuals constituting a group and its social network can limit our ability to detect real relationships between sociality and parasitism.

Taking this idea a step further, we also conducted a series of random knock-out simulations in which certain percentages of individuals were removed at random from the observed social network. Unlike with targeted removal, even removing $5 \%$ of individuals from the group at random impacted the results, and the strength of the relationship between centrality and infection dramatically decreased in approximately $90 \%$ of the subsequent models. Similar results were found when randomly removing $10 \%, 25 \%$ or $50 \%$ of individuals: fewer than $6 \%$ of models contained significant positive associations between centrality and infection. Our results corroborate simulation and empirical studies demonstrating that missing nodes can produce (more or less significant) measurement bias (Kossinets, 2006; Silk, 2018; Silk et al., 2015; Smith and Moody, 2013; Smith et al., 2017). Other studies investigated the effect of random missing nodes or targeted node removal, and not surprisingly, showed that targeted removal of more central individuals had the strongest effect on network measures (Smith and Moody, 2013; Smith et al., 2017). Moreover, as the proportion of individuals excluded increases, the probability that one or more central nodes are excluded also increases (Silk, 2018; Silk et al., 2015; Smith et al., 2017)(Smith et al. 2017, Silk 2017, Silk et al. 2015). Not all network measures are created equal, though, and metrics that indicate an individual's general reach within a network (such as betweenness or eigenvector centrality) are more sensitive to missing individuals (Silk et al., 2015; Smith et al., 2017). It is notable that, in our study, random removals of individuals impacted the results even more than did targeted removals of subsets of individuals, suggesting that, while the full network is always preferred, including complete subsets might be important. Ultimately, however, whether individuals are omitted intentionally or accidently, our results highlight the potential impacts of incomplete networks on the conclusions drawn.

Despite our results and the conclusions drawn from them, we do not intend to devalue the results of previous studies solely on these grounds. Incomplete networks can still provide robust results, providing that there is little imbalance as to who gets excluded (Borgatti et al., 2006; Silk et al., 2015). In our study, we focused only on excluding broad categories of individuals or used pseudo-random knock-outs, 
and we did not control for the specific social characteristics of the removed individuals. It is further possible that excluding particular individuals - super-spreaders, keystone individuals, policing individuals, alpha individuals - would have a much larger effect on the processes that occur on social networks than would excluding individuals with a less influential role. For instance, knocking out policers in a social group of pigtailed macaques greatly destabilised the structure of several social networks, setting the stage for reduced group cohesion (Flack et al., 2006). This is also reminiscent on the one hand of work investigating the effect of targeting specific individuals for heath interventions or information transmission: depending on which individual is targeted, information has a greater likelihood to spread in the community (e.g. Kim et al., 2015), and on the other hand, of work looking at the spread of an infectious disease or a parasite depending on which individual gets it first (e.g. Romano et al., 2016). Knowing the characteristics of individuals that play important roles in the sociality-parasitism relationship can help practitioners develop strategies for disease control (Romano et al., 2016; Rushmore et al., 2014) and captive population management (McCowan et al., 2008) for examples.

In conclusion, our study confirmed that social network centrality is positively related to geohelminth infection in Japanese macaques, but at the same time brought to light some nuances to that relationship. Studying an incomplete network showed different results compared with the whole-group network model, leading to different conclusions. A bit of caution and increasing research effort is therefore warranted in future studies.

\section{Acknowledgements}

We are grateful to the Cooperative Research Program of Kyoto University's Wildlife Research Center and the city of Kushima's Agency for Cultural Affairs for permitting this research. We thank Christof Neumann for statistical and programming support, accepting that all analytical decisions - and outstanding errors - are ours alone. We thank Dr. Zhang Peng for supporting this research and collaboration. 


\section{Funding}

At the time of the study, ZX was supported by a scholarship from Sumitomo Corporation. AJJM was supported by a Grant-in-Aid from the Japan Society for the Promotion of Science (JSPS: 16H06181). AC-N and EM-M were additionally supported by the German Research Foundation (AM 409/4-1 to Federica Amici, who we also thank) and the Universidad Cardenal Herrera-CEU (INDI 15/12, CEINDO 16/17). JD was supported by a postdoctoral fellowship from the JSPS.

\section{Conflict of interest disclosure}

The authors declare they have no conflict of interest relating to the content of this article.

\section{Author contributions}

ZX: Conceptualization; Data curation; Formal analysis; Writing - original draft.

AJJM: Conceptualization; Methodology; Project administration; Supervision; Writing - review and editing.

AC-N: Methodology; Investigation.

EM-M: Methodology; Investigation.

TS: Resources.

JD: Methodology; Supervision; Formal analysis; Writing - review and editing.

\section{Data, script and code availability}

The dataset (SP 1) and scripts are available on Git repository:

“https://github.com/XuZhihong-cn/Network_Centrality_analysis_and_KO-simulation"

The Supplementary information is available on Biorxiv: 
"https://www.biorxiv.org/content/10.1101/2021.06.07.447302v1.supplementary-material"

\section{References}

Albers, P. C. H., and H. de Vries, 2001, Elo-rating as a tool in the sequential estimation of dominance strengths: Animal Behaviour, v. 61, p. 489-495.

Altizer, S., C. L. Nunn, P. H. Thrall, J. L. Gittleman, J. Antonovics, A. A. Cunningham, A. P. Dobson, V. Ezenwa, K. E. Jones, A. B. Pedersen, M. Poss, and J. R. C. Pulliam, 2003, Social organization and parasite risk in mammals: Integrating theory and empirical studies: Annual Review of Ecology Evolution and Systematics, v. 34, p. 517-547.

Arneberg, P., 2002, Host population density and body mass as determinants of species richness in parasite communities: comparative analyses of directly transmitted nematodes of mammals: Ecography, v. 25, p. $88-94$.

Arneberg, P., A. Skorping, B. Grenfell, and A. F. Read, 1998, Host densities as determinants of abundance in parasite communities: Proceedings of the Royal Society of London. Series B: Biological Sciences, v. 265, p. $1283-1289$.

Bartoń, K., 2018, MuMIn: Multi-Model Inference.

Borgatti, S. P., 2005, Centrality and network flow: Social Networks, v. 27, p. 55-71.

Borgatti, S. P., K. M. Carley, and D. Krackhardt, 2006, On the robustness of centrality measures under conditions of imperfect data: Social Networks, v. 28, p. 124-136.

Borgatti, S. P., A. Mehra, D. J. Brass, and G. Labianca, 2009, Network Analysis in the Social Sciences: Science, v. 323, p. 892-895.

Briard, L., and V. O. Ezenwa, 2021, Parasitism and host social behaviour: a meta-analysis of insights derived from social network analysis: Animal Behaviour, v. 172, p. 171-182.

Brooks, M. E., K. Kristensen, K. J. van Benthem, A. Magnusson, C. W. Berg, A. Nielsen, H. J. Skaug, M. Machler, and B. M. Bolker, 2017, glmmTMB balances speed and flexibility among packages for zero-inflated generalized linear mixed modeling: The R journal, v. 9, p. 378-400.

Böhm, M., M. R. Hutchings, and P. C. L. White, 2009, Contact networks in a wildlife-livestock host community: identifying high-risk individuals in the transmission of bovine TB among badgers and cattle: PloS one, v. 4, p. e5016 -e5016.

Cain, D. W., and J. A. Cidlowski, 2017, Immune regulation by glucocorticoids: Nature Reviews Immunology, v. 17, p. 233-247.

Cords, M., M. J. Sheehan, and L. S. Ekernas, 2010, Sex and Age Differences in Juvenile Social Priorities in Female Philopatric, Nondespotic Blue Monkeys: American Journal of Primatology, v. 72, p. 193-205.

Croft, D. P., J. R. Madden, D. W. Franks, and R. James, 2011, Hypothesis testing in animal social networks: Trends in Ecology \& Evolution, v. 26, p. 502-507.

Crofton, H. D., 1971, QUANTITATIVE APPROACH TO PARASITISM: Parasitology, v. 62, p. 179-\&.

Csardi, G., and T. Nepusz, 2006, The igraph software package for complex network research: InterJournal, v. Complex Systems, p. 1695 \% 2018-03-01 16:58:00.

Duboscq, J., V. Romano, C. Sueur, and A. J. J. MacIntosh, 2016, Network centrality and seasonality interact to predict lice load in a social primate: Scientific Reports, v. 6, p. 13.

East, M. L., G. Wibbelt, D. Lieckfeldt, A. Ludwig, K. Goller, K. Wilhelm, G. Schares, D. Thierer, and H. Hofer, 2008, A HEPATOZOON SPECIES GENETICALLY DISTINCT FROM H. CANIS INFECTING 
SPOTTED HYENAS IN THE SERENGETI ECOSYSTEM, TANZANIA: Journal of Wildlife Diseases, v. 44 , p. $45-52$.

Ebersole, J. L., M. J. Steffen, J. Gonzalez-Martinez, and M. J. Novak, 2008, Effects of Age and Oral Disease on Systemic Inflammatory and Immune Parameters in Nonhuman Primates: Clinical and Vaccine Immunology, v. 15, p. 1067-1075.

Fallon, P. G., J. Gibbons, R. A. Vervenne, E. J. Richardson, J. C. F. Anthony, S. Kiarie, R. F. Sturrock, P. S. Coulson, A. M. Deelder, A. M. L. Jan, A. W. Thomas, and D. W. Dunne, 2003, Juvenile Rhesus Monkeys Have Lower Type 2 Cytokine Responses than Adults after Primary Infection with Schistosoma mansoni: The Journal of Infectious Diseases, v. 187, p. 939 -945.

Farine, D. R., 2017, A guide to null models for animal social network analysis: Methods Ecol Evol, v. 8, p. 13091320.

Farine, D. R., and H. Whitehead, 2015, Constructing, conducting and interpreting animal social network analysis: Journal of Animal Ecology, v. 84, p. 1144-1163.

Fedurek, P., and J. Lehmann, 2017, The effect of excluding juveniles on apparent adult olive baboons (Papio anubis) social networks: PLOS ONE, v. 12, p. e0173146.

Flack, J. C., M. Girvan, F. B. M. de Waal, and D. C. Krakauer, 2006, Policing stabilizes construction of social niches in primates: Nature, v. 439, p. 426-429.

Fleiss, J. L., and J. Cohen, 1973, The Equivalence of Weighted Kappa and the Intraclass Correlation Coefficient as Measures of Reliability: Educational and Psychological Measurement, v. 33, p. 613-619.

Freeland, W. J., 1976, Pathogens and the evolution of primate sociality: Biotropica, v. 8, p. 12-24.

Gillespie, T. R., 2006, Noninvasive assessment of gastrointestinal parasite infections in free-ranging primates: International Journal of Primatology, v. 27, p. 1129-1143.

Godfrey, S. S., 2013, Networks and the ecology of parasite transmission: A framework for wildlife parasitology: International Journal for Parasitology: Parasites and Wildlife, v. 2, p. 235-245.

Godfrey, S. S., C. M. Bull, R. James, and K. Murray, 2009, Network structure and parasite transmission in a group living lizard, the gidgee skink, Egernia stokesii: Behavioral Ecology and Sociobiology, v. 63, p. 1045 1056.

Gotoh, S., 2000, Regional differences in the infection of wild Japanese macaques by gastrointestinal helminth parasites: Primates, v. 41, p. 291-298.

Grassi, C., 2002, Sex differences in feeding, height, and space use in Hapalemur griseus: International Journal of Primatology, v. 23, p. 677-693.

Griffin, R. H., and C. L. Nunn, 2012, Community structure and the spread of infectious disease in primate social networks: Evolutionary Ecology, v. 26, p. 779-800.

Habig, B., and E. A. Archie, 2015, Social status, immune response and parasitism in males: a meta-analysis: Philosophical Transactions of the Royal Society B-Biological Sciences, v. 370, p. 17.

Habig, B., M. M. Doellman, K. Woods, J. Olansen, and E. A. Archie, 2018, Social status and parasitism in male and female vertebrates: a meta-analysis: Scientific Reports, v. 8, p. 13.

Hamilton, D. G., M. E. Jones, E. Z. Cameron, D. H. Kerlin, H. McCallum, A. Storfer, P. A. Hohenlohe, and R. K. Hamede, 2020, Infectious disease and sickness behaviour: tumour progression affects interaction patterns and social network structure in wild Tasmanian devils: Proceedings of the Royal Society B-Biological Sciences, v. 287, p. 7.

Hillegass, M. A., J. M. Waterman, and J. D. Roth, 2010, Parasite removal increases reproductive success in a social African ground squirrel: Behavioral Ecology, v. 21, p. 696-700.

Hinney, B., N. C. Wirtherle, M. Kyule, N. Miethe, K. H. Zessin, and P. H. Clausen, 2011, Prevalence of helminths in horses in the state of Brandenburg, Germany: Parasitology Research, v. 108, p. 1083-1091. 
Hoppitt, W. J. E., and D. R. Farine, 2018, Association indices for quantifying social relationships: how to deal with missing observations of individuals or groups: Animal Behaviour, v. 136, p. 227-238.

Horii, Y., I. Imada, T. Yanagida, M. Usui, and A. Mori, 1982, Parasite changes and their influence on the body weight of Japanese monkeys (Macaca fuscata fuscata) of the Koshima troop: Primates, v. 23, p. 416-431.

Izhar, R., and F. Ben-Ami, 2015, Host age modulates parasite infectivity, virulence and reproduction: Journal of Animal Ecology, v. 84, p. 1018-1028.

Jackson, J. A., A. J. Hall, I. M. Friberg, C. Ralli, A. Lowe, M. Zawadzka, A. K. Turner, A. Stewart, R. J. Birtles, S. Paterson, J. E. Bradley, and M. Begon, 2014, An Immunological Marker of Tolerance to Infection in Wild Rodents: Plos Biology, v. 12, p. 13.

Khan, M. N., M. S. Sajid, M. K. Khan, Z. Iqbal, and A. Hussain, 2010, Gastrointestinal helminthiasis: prevalence and associated determinants in domestic ruminants of district Toba Tek Singh, Punjab, Pakistan: Parasitology Research, v. 107, p. 787-794.

Kim, D. A., A. R. Hwong, D. Stafford, D. A. Hughes, A. J. O'Malley, J. H. Fowler, and N. A. Christakis, 2015, Social network targeting to maximise population behaviour change: a cluster randomised controlled trial: Lancet, v. 386, p. 145-153.

Klein, S. L., A. Cernetich, S. Hilmer, E. P. Hoffman, A. L. Scott, and G. E. Glass, 2004, Differential expression of immunoregulatory genes in male and female Norway rats following infection with Seoul virus: Journal of Medical Virology, v. 74, p. 180-190.

Kossinets, G., 2006, Effects of missing data in social networks: Social Networks, v. 28, p. 247-268.

Liao, Z. J., S. Sosa, C. F. Wu, and P. Zhang, 2018, The influence of age on wild rhesus macaques' affiliative social interactions: American Journal of Primatology, v. 80, p. 10.

Loehle, C., 1995, SOCIAL BARRIERS TO PATHOGEN TRANSMISSION IN WILD ANIMAL POPULATIONS: Ecology, v. 76, p. 326-335.

MacIntosh, A. J., A. D. Hernandez, and M. A. Huffman, 2010, Host age, sex, and reproductive seasonality affect nematode parasitism in wild Japanese macaques: Primates, v. 51, p. 353-64.

MacIntosh, A. J. J., 2014, Ecology and Epidemiology of Nematode Infection in Japanese Macaques

Building an Empirical Model: Primate Research, v. 30, p. 23-51.

MacIntosh, A. J. J., A. Jacobs, C. Garcia, K. Shimizu, K. Mouri, M. A. Huffman, and A. D. Hernandez, 2012, Monkeys in the Middle: Parasite Transmission through the Social Network of a Wild Primate: PLoS ONE, v. 7.

McCowan, B., K. Anderson, A. Heagarty, and A. Cameron, 2008, Utility of social network analysis for primate behavioral management and well-being: Applied Animal Behaviour Science, v. 109, p. 396-405.

McDonald, M., and S. Johnson, 2014, 'There's an app for that': a new program for the collection of behavioural field data: Animal Behaviour, v. 95, p. 81-87.

Modrý, D., B. Pafčo, K. J. Petrželková, and H. Hasegawa, 2018, Parasites of Apes: An Atlas of Coproscopic Diagnostics, Edition Chimaira.

Moller, A. P., R. Dufva, and K. Allander, 1993, PARASITES AND THE EVOLUTION OF HOST SOCIALBEHAVIOR: Advances in the Study of Behavior, Vol 22, v. 22, p. 65-102.

Müller Klein, N., M. Heistermann, C. Strube, M. Franz, O. Schülke, and J. Ostner, 2019, Exposure and susceptibility drive reinfection with gastrointestinal parasites in a social primate: Functional Ecology.

Neumann, C., J. Duboscq, C. Dubuc, A. Ginting, A. M. Irwan, M. Agil, A. Widdig, and A. Engelhardt, 2011, Assessing dominance hierarchies: validation and advantages of progressive evaluation with Elo-rating: Animal Behaviour, v. 82, p. 911-921.

Neumann, C., and L. Kulik, 2014, EloRating: Animal Dominance Hierarchies by Elo Rating. 
Nunn, C. L., 2012, Primate Disease Ecology in Comparative and Theoretical Perspective: American Journal of Primatology, v. 74, p. 497-509.

Nunn, C. L., F. Jordan, C. M. Mc-Cabe, J. L. Verdolin, and J. H. Fewell, 2015, Infectious disease and group size: More than just a numbers game: Philosophical Transactions of the Royal Society B: Biological Sciences, v. 370 .

Otterstatter, M. C., and J. D. Thomson, 2007, Contact networks and transmission of an intestinal pathogen in bumble bee (Bombus impatiens) colonies: Oecologia, v. 154, p. 411-421.

Poulin, R., 2007, Are there general laws in parasite ecology?: Parasitology, v. 134, p. 763-776.

Powell, S. N., M. M. Wallen, M. L. Miketa, E. Krzyszczyk, V. Foroughirad, S. Bansal, and J. Mann, 2020, Sociality and tattoo skin disease among bottlenose dolphins in Shark Bay, Australia: Behavioral Ecology, v. 31, p. 459-466.

R Development Core Team, 2019, R: A Language and Environment for Statistical Computing.

Roberts, C. W., W. Walker, and J. Alexander, 2001, Sex-associated hormones and immunity to protozoan parasites: Clinical Microbiology Reviews, v. 14, p. 476-+.

Roberts, S. G. B., and A. I. Roberts, 2020, Social and ecological complexity is associated with gestural repertoire size of wild chimpanzees: Integrative Zoology, v. 15, p. 276-292.

Romano, V., J. Duboscq, C. Sarabian, E. Thomas, C. Sueur, and A. J. J. MacIntosh, 2016, Modeling infection transmission in primate networks to predict centrality-based risk: American Journal of Primatology, v. 78, p. 767-779.

Rousset, F., F. Thomas, T. deMeeus, and F. Renaud, 1996, Inference of parasite-induced host mortality from distributions of parasite loads: Ecology, v. 77, p. 2203-2211.

Rushmore, J., D. Bisanzio, and T. R. Gillespie, 2017, Making New Connections: Insights from Primate-Parasite Networks: Trends in Parasitology, v. 33, p. 547-560.

Rushmore, J., D. Caillaud, R. J. Hall, R. M. Stumpf, L. A. Meyers, and S. Altizer, 2014, Network-based vaccination improves prospects for disease control in wild chimpanzees: Journal of the Royal Society Interface, v. 11, p. 10.

Sandel, A. A., J. Rushmore, J. D. Negrey, J. C. Mitani, D. M. Lyons, and D. Caillaud, 2021, Social Network Predicts Exposure to Respiratory Infection in a Wild Chimpanzee Group: Ecohealth, p. 12.

Sarabian, C., R. Belais, and A. J. J. Maclntosh, 2018a, Feeding decisions under contamination risk in bonobos: Philosophical Transactions of the Royal Society B-Biological Sciences, v. 373, p. 13.

Sarabian, C., V. Curtis, and R. McMullan, 2018b, Evolution of pathogen and parasite avoidance behaviours: Philosophical Transactions of the Royal Society B-Biological Sciences, v. 373, p. 7.

Shaw, D. J., B. T. Grenfell, and A. P. Dobson, 1998, Patterns of macroparasite aggregation in wildlife host populations: Parasitology, v. 117, p. 597-610.

Silk, M. J., 2018, The next steps in the study of missing individuals in networks: a comment on Smith et al. (2017): Social Networks, v. 52, p. 37-41.

Silk, M. J., A. L. Jackson, D. P. Croft, K. Colhoun, and S. Bearhop, 2015, The consequences of unidentifiable individuals for the analysis of an animal social network: Animal Behaviour, v. 104, p. 1-11.

Smith, J. A., and J. Moody, 2013, Structural effects of network sampling coverage I: Nodes missing at random: Social Networks, v. 35, p. 652-668.

Smith, J. A., J. Moody, and J. H. Morgan, 2017, Network sampling coverage II: The effect of non-random missing data on network measurement: Social Networks, v. 48, p. 78-99.

Stephens, P. R., P. Pappalardo, S. Huang, J. E. Byers, M. J. Farrell, A. Gehman, R. R. Ghai, S. E. Haas, B. Han, A. W. Park, J. P. Schmidt, S. Altizer, V. O. Ezenwa, and C. L. Nunn, 2017, Global Mammal Parasite Database version 2.0: Ecology, v. 98, p. 1476-+. 
Sueur, C., O. Petit, A. De Marco, A. T. Jacobs, K. Watanabe, and B. Thierry, 2011, A comparative network analysis of social style in macaques: Animal Behaviour, v. 82, p. 845-852.

VanderWaal, K. L., E. R. Atwill, S. Hooper, K. Buckle, and B. McCowan, 2013, Network structure and prevalence of Cryptosporidium in Belding's ground squirrels: Behavioral Ecology and Sociobiology, v. 67, p. 1951 1959.

Venables, W. N., and B. D. Ripley, 2002, Modern Applied Statistics with S, Springer.

Watanabe, K., 2008, A Review of 50 Years of Research on the Japanese Monkeys of Koshima: Status and Dominance, p. 405-417.

Webber, Q. M. R., R. M. Brigham, A. D. Park, E. H. Gillam, T. J. O'Shea, and C. K. R. Willis, 2016, Social network characteristics and predicted pathogen transmission in summer colonies of female big brown bats (Eptesicus fuscus): Behavioral Ecology and Sociobiology, v. 70, p. 701-712.

Webber, Q. M. R., D. C. Schneider, and E. Vander Wal, 2020, Is less more? A commentary on the practice of 'metric hacking' in animal social network analysis: Animal Behaviour, v. 168, p. 109-120.

Weber, N., S. P. Carter, S. R. X. Dall, R. J. Delahay, J. L. McDonald, S. Bearhop, and R. A. McDonald, 2013, Badger social networks correlate with tuberculosis infection: CURRENT BIOLOGY, v. 23, p. R915R916.

White, L. A., J. D. Forester, and M. E. Craft, 2017, Using contact networks to explore mechanisms of parasite transmission in wildlife: Biological Reviews, v. 92, p. 389-409.

Wilson, K., O. N. Bjornstad, A. P. Dobson, S. Merler, G. Polayen, S. E. Randolph, A. F. Read, and A. Skorping, 2002, Heterogeneities in Macroparasite Infections: Patterns and Processes: International Journal for Parasitology, v. volume 26, p. 1009-1024(16).

Wood, E. L. D., J. B. Matthews, S. Stephenson, M. Slote, and D. H. Nussey, 2013, Variation in fecal egg counts in horses managed for conservation purposes: individual egg shedding consistency, age effects and seasonal variation: Parasitology, v. 140, p. 115-128.

Woolhouse, M. E. J., 1998, Patterns in parasite epidemiology: The peak shift: Parasitology Today, v. 14, p. 428434.

Yamagiwa, J., and D. Hill, 1998, Intraspecific variation in the social organization of Japanese macaques: Past and present scope of field studies in natural habitats: Primates, v. 39, p. 257-273. 